\title{
Length of stay in the emergency department and its associated factors among pediatrics patients attending at Wolaita Sodo University Teaching and Referral Hospital, Southern, Ethiopia, 2021.
}

Nega Tezera ( $\nabla$ tezera.nega@gmail.com )

University of Gondar https://orcid.org/0000-0003-3573-1869

Kiberalem Bisete Negasi

Wolita Sodo University

Almaze Tefera

University of Gondar

Migbaru Getachew

Wolita Sodo University

\section{Research Article}

Keywords: Ethiopia, Length of Stay, Pediatrics Emergency, Wolaita

Posted Date: December 2nd, 2021

DOI: https://doi.org/10.21203/rs.3.rs-1132591/v1

License: (c) (1) This work is licensed under a Creative Commons Attribution 4.0 International License.

Read Full License 


\section{Abstract \\ Background}

Pediatrics emergency department length of stay; is the time between emergency department arrival and discharge, admission, or referred. Globally, there is a rising in the need for emergency department visits, which is very high in pediatric patients causing a longer length of stay, which is a global challenge and the bottle neck of hospitals that increase the risk of patients, morbidity, mortality, and reduce satisfaction.

\section{Objective}

This study aimed to assess the length of stay and its associated factors in the pediatric emergency department, Wolaita Sodo University Hospital, 2021.

\section{Methods}

An institution-based cross-sectional study was conducted from March 15 to May 15/ 2021. A Systematic sampling technique was used to select 422 study participants. Semi-structured interviewer-administered questionnaires and chart reviews were used to collect the data. The data were entered in Epi Data version 4.6 and analyzed with SPSS version 26. Descriptive statistics were applied to describe the prevalence, pediatrics, emergency department length of stay with a $95 \%$ confidence interval. Bi-variable and multivariable logistic regression analysis were used to identify the factors associated with length of stay and the significant level was declared at p-value $\leq 0.05$ on AOR and $95 \%$ confidence interval

\section{Results}

The proportion of prolonged pediatric emergency department length of stay was $79.70 \%$ ( $95 \% \mathrm{Cl} ; 75.7$, 83.6). Night time arrival $[A O R=3.19,95 \% \mathrm{Cl}(1.14,8.98)]$, weekend arrival [AOR=4.25 95\% $\mathrm{Cl}(1.63,11.12]$, ordered imaging study [AOR $=2.8295 \% \mathrm{Cl}(1.49,5.35)]$, not got ordered medication in the hospital [AOR = $2.0595 \% \mathrm{Cl}(1.04,4.03)]$ orange triage category $[A O R=4.01,95 \% \mathrm{Cl}(1.60,10.05)]$, and duration of pain 1324 hours $[\mathrm{AOR}=0.29,95 \% \mathrm{Cl}(0.89,0.98)]$, were significantly associated with length of stay

\section{Conclusion}

The proportion of prolonged pediatrics emergency department length of stay was high. To decrease the length of stay, it is better to support the investment of resources on solving these benchmarks.

\section{Background}


Pediatrics emergency department (ED) length of stay (LOS): is the time between ED arrival and ED discharge, admission, or referral to another health facility (1). ED in the hospital is designed for rapid assessment and stabilization with the patient arriving at the hospital in need of immediate care must be accessible 24 hours a day and timeliness is considered an essential component in the quality of ED care (2-4). ED has become an increasingly important unit in the healthcare delivery system and nowadays it is considered the primary doorway for inpatient admissions, discharge, and refers $(5,6)$.

Prolonged pediatrics ED length of stay are universal problem with differing prevalence across the globe, for instance, $31.3 \%$ in Guangzhou, China, $25.7 \%$ in north Taiwan, and $16.4 \%$ in Calabar Southern Nigeria(7-9).Globally in the last 20 years, there is an imbalance between emergency service supply and demand, and annual ED visits increased faster than the growing population, leading to an increase in the number of ED visits resulting in prolonged ED stays $(10,11)$.

Prolonged pediatrics emergency department LOS is not only associated with reduced quality of care, but also having an impact on socio-economic problems to the parents, hospital occupancy rate, increased constrictions on health service resources, more over it has a significant effect on patient safety by an increased risk of hospital-acquired diseases, morbidity, mortality, and reduce patient satisfaction $(6,12-$ 14).

Different works of literature reported that prolonged ED stay leads to an increased mortality rate by $15 \%-30 \%$ and showed as evidence of poor hospital performance, it also an independent risk factor for pneumonia and each hour increases the risk by approximately $20 \%$,regarding this and many other consequences of prolonged LOS is a global challenge(15-17).Moreover shorter hospital stays reduce unnecessary medical costs and increase bed turnover rate that helps to raise the profit margin of the institution, in addition to reducing total social-related charges $(5,9,18)$.

Even though there is variability in the emergency department LOS, several factors contributed to prolonged pediatrics ED length of stay. Of these restricted capacities of the health care system, professional inabilities to correctly triage, lack of decision, utilization of health care such as imaging or laboratory investigations, and increased flow of non-urgent cases to EDs are the most common predisposing factors for prolonged pediatric ED length of stay. $(5,19,20)$.

Subsequently, the incidence of communicable and preventable diseases like malaria, diarrheal disease, and pneumonia are high in sub-Saharan African countries and account for $70 \%$ of pediatric emergency admissions, this and the rising of the prevalence of non-communicable diseases may increase pediatrics emergency department length of stay $(9,21)$.

Pediatric emergency subspecialty is not yet well developed in most low and middle-income countries (LMICs) and pediatrics emergency unit care are provided by the general pediatrician and minimal expertise in pediatrics emergency medicine thus, critical gaps in pediatric emergency care exist which may negatively affect patient outcomes and this situation is worse in Ethiopia, where the ratio of pediatricians per population is low and there is no emergency pediatrician $(9,22)$. 
ED overcrowding is an international worry and signifies a global crisis that can influence the quality of service caused by the prolonged length of stay and prolonged LOS also causes overcrowding $(9,23,24)$. WHO and FMOH were designing ETAT training and triage standards for health care providers as possible solutions to reduce PED length. However, prolonged pediatrics ED length of stay is still global challenge (14).

There is limited study done in Ethiopia concerning factors associated with LOS in the pediatric ED. Since children are the future of one country and in need of special care have to be emphasized, particularly their health status and providing high-quality care (18). Therefore, this study aimed to assess the pediatric emergency department length of stay and its associated factors among pediatric patients visiting PED of Wolaita Sodo teaching and referral hospital.

Prolonged pediatric ED length of stay is a global challenge that predisposes patients to increased risk of morbidity, mortality, reduced satisfaction, socio-economic burden on the parents, and increased constraints on health facility resources. Prolonged LOS can cause overcrowding and ED overcrowding is an international worry and signifies a global crisis that can influence the quality of service.

ED LOS is a critical component of quality assurance monitoring and is positively associated with patient morbidity, mortality, and reduced patient satisfaction. Children are prone to risks and if they stay longer in the emergency department, the higher the risks are, therefore identification of possible factors for LOS will help to take a targeted intervention to avert prolonged LOS.

Data regarding ED LOS in Ethiopia is scarce. Therefore, the findings of this study will give a snapshot picture for planning to pediatrics ED length of stay, policy-making as well as ED interventions to address problems related to prolonged PED stay. In addition; this study will contribute to the achievement of the Sustainable Development Goal particularly (SDG3). Besides, this study will examine variables like occupation, marital status, prior treatment, and educational status of parents which are not included in other studies, therefore; this study will revise new information on the association of LOS in pediatrics ED.

And, the findings will create awareness in the hospital about the problem and contribute to formulating appropriate interventions to reduce LOS in pediatrics ED. Furthermore, the findings of the study will contribute to battle prolonged LOS.

\section{Methods}

\section{Study Design and Setting}

An Institutional based cross-sectional study was conducted at Wolaita Sodo University Teaching Referral Hospital in Wolaita Sodo town from March 15 to May15, 2021GC. Wolaita Sodo town is situated at 313 $\mathrm{km}$ away from Addis Ababa, Ethiopia, and it is one of the zonal administrative units of towns in the Southern Region of Ethiopia that consist of 10 kebeles. The town is divided in to 4 administrative subcities. According to the 2019 Wolaita Sodo Town administrative health office report, Wolaita Sodo 
Town has a total population of 200,450 (2017) comprising $98,221(49 \%)$ males and $102,229(51 \%)$ females of these 4963 were women in the reproductive age group (15-49 years), 28,499 under-five age children and 4576 infants less than one year of age. Functioning health facilities in the town include two Hospitals (one governmental and one private), 3 health centers, 19 medium and lower level clinics and 17 health posts $(25,26)$

WSUTRH was established in 2007Gc and now WSUTRH provides general outpatient and inpatient services including medical, surgical, pediatric, psychiatric, ophthalmic, emergency, gynecology, and obstetrics care. The hospital serves more than three million people in Wolaita and neighboring zones with an average bed capacity of 416 and about 1155 health professionals and other technical and supportive staff (27).

The pediatrics department has four major wings: pediatric Emergency admission unit, Neonatal Intensive Care Unit (NICU), pediatric surgical admission ward, pediatric medical admission ward, and stabilization center (SC) unit with the total 133patient beds in the five wings and the pediatric emergency department has 29 beds(27).

\section{Participants of the study}

All children who are attending the pediatric emergency department of Wolaita Sodo University Hospital were the source population. Children who were attending the pediatric emergency department during the data collection period were included in the study. However, children with immediate death at arrival and critically ill patients were excluded from the study.

\section{Sample size determination and sampling procedure}

The sample size was calculated by using a single population proportion formula based on the following statistical assumptions; $P=50 \%$ ( Assuming the proportion of pediatrics emergency department length of stay to be $50 \%$, since there is no published study conducted in the study area of interest) $95 \%$ confidence level, and $5 \%$ margin of error. Based on this formula and after adding a $10 \%$ nonresponse rate, the total sample size was 422 .Thus, data were collected from 422 pediatric patients attending the pediatric emergency department.

Systematic random sampling technique was used to select the actual study participants in Wolaita Sodo University hospital attending the pediatric emergency department. To select the desired sample of pediatrics patients among attendants of Wolaita Sodo University Teaching and Referral Hospital, the average number of pediatrics patients who visited the pediatric emergency department of Wolaita Sodo University Teaching and Referral Hospital within the last three months before the study was identified from the client registration. On the base of this, the expected client flow rate during the study period (one month) was estimated to be 1200 . Then, the sampling interval $(k)$ was calculated by dividing the expected number of mothers visiting the unit during the study period $(\mathrm{N})$ with the determined sample size (n) of respondents $(1200 / 422=2.8)$. Finally, using a systematic random sampling technique, one in every 3 attendant children pairs was selected until the required sample was reached. 


\section{Data collection tools and procedures}

The required data were collected using face-to--to-face interview through semi-structured questionnaires and chart reviews, which were adapted and modified from the previous studies $(5,10,14,22,28,29)$. The questionnaire contains four parts, the first part contains 13 questions regarding socio-demographic characteristics of the study participants, the second part contains five questions related to time factors affecting length of stay, the third part contains 11 questions related to clinical factors of the participant affecting ED length of stay, and the fourth part contains 16 questions related to organizational factors.

The data was collected through training five nurses for data collection and one nurse for supervision who can speak fluently both Amharic and Wolaitigna languages. The pre-test was done on the twenty one respondents at Arbaminch referral hospital. Inter-observer variability was also checked and adjustment was made based on the results of the pretest.

The study participants' language fluency were asked and either Wolaitigna or Amharic interviews were applied by their choice, then after guarantying, their willingness to take part in the study and verbal consent and assent were obtained. Data were collected by trained data collectors from the patients following presentation, admission, and at the time of discharge from the ED through respondent interview and medical record review. The data collection procedure was illustrated as follows: first, eligible patients were identified by data collectors at the triage room while resident staff triaging patients on arrival. Hence, at arrival, time and other presentation characteristics were recorded the triage room. Following this, other information such as socio-demographic characteristics and other organizational-related factors were obtained by interviews and chart review at different treatment points, and after the patient the gate stabilized, finally, information such as diagnostic investigations and overall treatment done were recorded from medical records, whereas the overall length of stay at the department and final disposition were recorded right at the time of the patient was discharged, from the ED. Later, the essential time-related factors were ED arrival time and the overall length of stay between presentation and discharge from ED.

\section{Operational Definitions:}

\section{Pediatrics emergency department Length of stay (PEDLOS)}

it is defined as the time between ED arrival and ED discharge, admission, or referral to another health facility which should not exceed 24 hours according to the Ethiopian federal minister of health (30).

\section{Prolonged length of stay}

defined as patient stays in the emergency department more than 24hrs. (30).

\section{Not prolonged length of stay}

when a patient stays in the emergency department less than $24 \mathrm{hrs.} \mathrm{(30).}$

\section{Waiting time}


is a time started from the patient arrived to ED until triaged by health care providers, which should not exceed 5 minutes of arrival to ED. (31)

\section{Data Processing And Analysis}

After checking for completeness, data were coded and entered into Epi Data version 4.6software and then exported to SPSS version 26.0 for further data analysis. Descriptive statistical analyses were computed and important variables were presented by percent frequency tables and figures. The outcome variable pediatrics emergency department LOS was dichotomized and coded as " 1 " for not prolonged ED length of stay "0" for prolonged ED length of stay. To say not prolonged ED length of stay, the total time of stay in PED should be less than or equal to twenty-four hours ( $\leq 24 \mathrm{hrs}$.), and the prolonged LOS is if the total time of stay is greater than twenty-four hours ( $>24 \mathrm{hrs}$.). Standardized residuals were analyzed to check the presence of outliers, as well as multi-Collinearity was checked using the variance inflation factor, and variables with a variance inflation factor greater than ten were removed. Model fitness was tested using the Hosmer-Lemeshow goodness of fit test.

To examine the association between the independent and outcome factors, initially, bivariable logistic regression analysis was conducted. Independent variables with a p-value $\leq$ of 0.25 in the bivariable logistic regression analysis were included in the multivariable logistic regression analysis to control for all possible confounders and identify the significant factors. The strength of the association between the dependent and independent variables was measured using adjusted odds ratios with $95 \% \mathrm{Cl}$ and $\mathrm{p}$-value of 0.05 or less was used for the final interpretation of statistical significance.

\section{Results}

\section{Socio-demographic characteristics of the respondents}

Out of the total, 422pediatrics patient-attendant pair participated in the study, of which $408(96.68 \%$.) were respond. The Median age of the study participants was 2.06 years with an Inter-Quartile Range (IQR) of 0.66-6.23 years. More than one-third (40.4\%) of them were under the age group of $\leq 1$ year category. More than half $(55.4 \%)$ of the study participants were female and two hundred thirty-three $(57.1 \%)$ of the participants were urban dwellers.

Table1:Socio-demographic characteristics of respondents at the pediatric emergency departments in Wolaita Sodo University Teaching and Referral Hospital, South Ethiopia, Jun 2021. ( $n=408)$ 


\begin{tabular}{|c|c|c|c|}
\hline $\begin{array}{l}\text { Socio-demographic } \\
\text { characteristics }\end{array}$ & Category & Number & Percent \\
\hline \multirow[t]{6}{*}{ Age } & $\leq 1$ & 165 & 49.40 \\
\hline & $1.1-3$ & 69 & 16.90 \\
\hline & $3.1-5$ & 56 & 13.70 \\
\hline & $5.1-6$ & 23 & 5.60 \\
\hline & $6.1-12$ & 66 & 16.20 \\
\hline & $\geq 12.01$ & 29 & 7.10 \\
\hline \multirow[t]{2}{*}{ Sex } & Male & 182 & 44.60 \\
\hline & Female & 226 & 55.40 \\
\hline \multirow[t]{2}{*}{ Residence } & Rural & 175 & 42.90 \\
\hline & Urban & 233 & 57.10 \\
\hline \multirow[t]{3}{*}{ Distance to hospital in km } & $\leq 7 \mathrm{~km}$ & 143 & 35.00 \\
\hline & $8-25 \mathrm{~km}$ & 53 & 13.00 \\
\hline & $>26 \mathrm{~km}$ & 221 & 51,70 \\
\hline \multirow[t]{5}{*}{ Religion } & Orthodox & 178 & 43.60 \\
\hline & Muslim & 33 & 8.10 \\
\hline & Protestant & 134 & 32.80 \\
\hline & Catholic & 53 & 13.00 \\
\hline & $\star$ Other $^{1}$ & 10 & 2.50 \\
\hline \multirow[t]{4}{*}{ Marital status } & Married & 267 & 65.40 \\
\hline & Single & 96 & 23.50 \\
\hline & Divorced & 28 & 6.90 \\
\hline & Widowed & 17 & 4.20 \\
\hline \multirow[t]{2}{*}{ Educational status } & Attending formal education & 225 & 55.10 \\
\hline & No formal education & 183 & 44.90 \\
\hline \multirow[t]{3}{*}{ Formal education level } & Primary & 93 & 22.80 \\
\hline & Secondary & 52 & 12.70 \\
\hline & Above & 80 & 19.60 \\
\hline
\end{tabular}




\begin{tabular}{|c|c|c|c|}
\hline $\begin{array}{l}\text { Socio-demographic } \\
\text { characteristics }\end{array}$ & Category & Number & Percent \\
\hline \multirow[t]{5}{*}{ Occupation } & Governmental & 93 & 22.80 \\
\hline & Private & 109 & 26.70 \\
\hline & Farmer & 166 & 40.70 \\
\hline & Delay labor & 31 & 7.60 \\
\hline & Others $^{2}$ & 9 & 2.20 \\
\hline \multirow[t]{4}{*}{ Language spoken } & One & 104 & 25.50 \\
\hline & Two & 269 & 65.90 \\
\hline & Three & 31 & 7.60 \\
\hline & More than three & 4 & 1.00 \\
\hline \multirow[t]{4}{*}{ Monthly income in ETB } & $\leq 500$ & 33 & 8.10 \\
\hline & $500-1000$ & 51 & 12.50 \\
\hline & $1001-200$ & 54 & 13.20 \\
\hline & $>2000$ & 270 & 66.20 \\
\hline
\end{tabular}

\subsection{Clinical related characteristics of respondents}

Of the total respondents ( $n=408$ ) one-hundred forty-five (35.5\%) of the respondents came with a complaint of respiratory symptom problems. Nearly two-thirds (61.3\%) of the respondents was on an alert level of conciseness. Most, 319(54.9\%) got prior treatment before arriving at ED. Co- morbid illness were reported by eighty-nine (21.1\%) of the respondents. Respiratory problems were the most common initial diagnosis and all responds had the same final diagnosis with initial diagnosis. 
Table 2

Clinical related characteristics of respondents

\begin{tabular}{|c|c|c|c|}
\hline Presenting characteristics & Category & Number & Percent (\%) \\
\hline \multirow[t]{5}{*}{ Mode of arrival } & By taxi & 169 & 41.40 \\
\hline & By ambulance & 37 & 9.10 \\
\hline & By public transport & 167 & 40.90 \\
\hline & On foot & 17 & 4.20 \\
\hline & ${ }^{*}$ Others ${ }^{1}$ & 18 & 4.40 \\
\hline \multirow[t]{3}{*}{ Referral status } & Self & 250 & 61.30 \\
\hline & From health center & 144 & 35.30 \\
\hline & From other hospitals & 14 & 3.40 \\
\hline \multirow[t]{6}{*}{ Chief compliant } & RS & 148 & 36.30 \\
\hline & CVS & 35 & 8.60 \\
\hline & GI & 72 & 17.60 \\
\hline & CNS & 34 & 8.30 \\
\hline & Trauma & 57 & 14 \\
\hline & Fever & 62 & 15.20 \\
\hline \multirow[t]{2}{*}{ Prior treatment } & Yes & 319 & 78.20 \\
\hline & No & 89 & 21.80 \\
\hline \multirow[t]{4}{*}{ Prior treatment place } & Home remedy & 158 & 49.50 \\
\hline & Health facility & 152 & 47.60 \\
\hline & Alternative care & 5 & 1.60 \\
\hline & *0ther ${ }^{2}$ & 4 & 1.30 \\
\hline \multirow[t]{2}{*}{ Preexisting comorbidity } & Yes & 89 & 21.80 \\
\hline & No & 319 & 78.20 \\
\hline \multirow[t]{4}{*}{ Triage Category } & Red & 91 & 22.30 \\
\hline & Orange & 132 & 32.40 \\
\hline & Yellow & 112 & 27.50 \\
\hline & Green & 73 & 17.90 \\
\hline
\end{tabular}




\begin{tabular}{|lllll|}
\hline Presenting characteristics & Category & Number & Percent (\%) \\
\hline Mental status & Alert & 250 & 61.30 \\
\cline { 2 - 4 } & Comatose & 37 & 9.10 \\
\cline { 2 - 4 } & Confused & 121 & 31.10 \\
\cline { 2 - 3 } & &
\end{tabular}

Of the total respondents $(n=408)$, nearly half of them (48.50\%) arrived at ED in the morning. Moreover, most respondents $319(78.10 \%)$ came to ED on workdays. All of the respondents had ordered an investigation and from those, all of them had laboratory investigations and $245(60 \%)$ of them had imaging studies.

\section{Time and organizational related factors of respondents (table 3)}




\begin{tabular}{|c|c|c|c|}
\hline Factors & Category & Number & Percent \\
\hline \multirow[t]{3}{*}{ Time of arrival } & Moring & 198 & 48.50 \\
\hline & Afternoon & 141 & 34.60 \\
\hline & Night & 69 & 16.90 \\
\hline \multirow[t]{2}{*}{ Day of arrival } & Workday & 319 & 78.20 \\
\hline & Weekend & 89 & 21.80 \\
\hline \multirow[t]{2}{*}{ Waiting time } & $\leq 5$ minute & 211 & 51.70 \\
\hline & $>5$ minute & 197 & 48.30 \\
\hline \multirow[t]{5}{*}{ Duration of pain } & $\leq 12$ hours & 49 & 12.00 \\
\hline & 13-24 hours & 47 & 11.50 \\
\hline & $25-48$ hours & 58 & 14.20 \\
\hline & 49-72 hours & 100 & 24.50 \\
\hline & $\geq 73$ hours & 154 & 37.70 \\
\hline \multirow[t]{2}{*}{ Ordered investigations } & Yes & 408 & 100.00 \\
\hline & No & 0 & 0.00 \\
\hline \multirow[t]{2}{*}{ Laboratory test } & Yes & 408 & 100.00 \\
\hline & No & 0 & 0.00 \\
\hline \multirow[t]{2}{*}{ Imaging studies } & Yes & 245 & 60.00 \\
\hline & No & 163 & 40.00 \\
\hline \multirow[t]{2}{*}{ Got ordered medication in the hospital } & Yes & 247 & 60.70 \\
\hline & No & 160 & 39.30 \\
\hline \multirow[t]{2}{*}{ Number investigations } & 1 & 41 & 10.00 \\
\hline & $\geq 2$ & 367 & 90.00 \\
\hline \multirow[t]{2}{*}{ Got ordered investigations } & Yes & 376 & 92.20 \\
\hline & No & 32 & 7.80 \\
\hline \multirow[t]{2}{*}{ Staff shift exchange experience } & Yes & 365 & 89.50 \\
\hline & No & 43 & 10.50 \\
\hline \multirow[t]{2}{*}{ Number shift exchange experience } & $\leq 3$ & 100 & 27.40 \\
\hline & $\geq 4$ & 265 & 72.60 \\
\hline
\end{tabular}




\section{Outcome of the respondents}

More than two-thirds (45.5\%) of the respondents were discharged from pediatrics ED by dint of orders of physicians and a few $1.2 \%$ of the participant were discharged against medical advice. 2 minutes, 3 minutes, and 10 minutes were the minimum time taken started from the physician ordered till the participants discharge, admitted, and referred, respectively, congruently the maximum time taken to discharge were 60 minutes, 410 minutes to refer and 417 minutes were taken admitted.

Figure 3: Outcome of pediatric patent from pediatrics emergency department of Wolaita Sodo University Teaching and Referral Hospital, South Ethiopia Jun 2021. $(n=408)$

\section{Length of stay in pediatrics emergency department}

The proportion of prolonged length of stay was $325(79.70 \%)$ of the respondents were stayed more than 24 hours in pediatrics ED and the rest, $83(20.30 \%)$ had a length of stay $\leq$ of 24 hours. The minimum length of stay in Wolaita Sodo University Teaching and Referral Hospital pediatrics emergency department length of stay was 1 hour which accounts for $1 \%$ of the participants, the median length of stay was 50.50 hours and the maximum ED length of stay was 384 hours accounting $0.2 \%$ of the respondents.

\section{Factors associated with length of stay}

The bivariable analysis showed that residency, time of arrival, date of arrival, duration of pain, preexisting comorbidity, triage categories, imaging study, referral status, number of investigations, admission, and, getting the ordered medications in the hospital were significantly associated with length of stay at Pvalue $<0.2$.In the multivariable analysis, date of arrival, time of arrival, duration of pain, triage categories, imaging study, and, getting all order medications in the hospital remained significant.

The odds of a prolonged stay at the PED among respondents who presented to the emergency department during the weekend were 4.25times (AOR=4.25; 95\% Cl: $1.63,11.12)$ higher than those who presented on workdays. Night-time presentation of the patients to ED was 3.19 times (AOR=3.19; 95\% Cl: $1.14,8.98)$ more likely to have prolonged length of stay than a morning presentation.

The likely hood of experiencing a prolonged length stay at the PED among those under the orange triage category was four times (AOR=4.01; $95 \% \mathrm{Cl}: 1.60,10.05)$ higher than those with triage category of green. The probability of experiencing a prolonged length of stay at the PED among participants who did not find all order medications in the hospital was2.05 times (AOR=2.05; 95\% Cl: 1.04, 4.03) higher than to those who found the ordered medications in the hospital. The odds of experiencing a prolonged length stay at the PED among those having imaging diagnostic investigation were 2.83 times (AOR, $2.8295 \% \mathrm{Cl}$, 1.49-5.35) higher than those having no imaging diagnostic investigation. 
Furthermore, the results of this study showed that the length of stay was $71 \%$ (AOR $=0.29 ; 95 \% \mathrm{Cl}$ : 0.87 0.98) less in a participant with a duration of pain from 13-24 hours compared to those who had less than 12 hours duration of pain. 
Table 4

Bivariable and Multivariable logistic regression analysis of factors associated with length of stay among pediatric patients attending pediatric ED of Wolaita Sodo University Teaching and referral hospital south Ethiopia 2021 ( $n=408$ )

\begin{tabular}{|c|c|c|c|c|c|c|}
\hline \multirow[t]{2}{*}{ Variables } & & \multicolumn{2}{|c|}{ Length of stay } & \multirow{2}{*}{$\begin{array}{l}\text { COR }(95 \% \\
\text { Cl) }\end{array}$} & \multirow{2}{*}{$\begin{array}{l}\text { AOR }(95 \% \\
\text { Cl) }\end{array}$} & \multirow{2}{*}{$\begin{array}{l}\mathrm{P} \text { - } \\
\text { value }\end{array}$} \\
\hline & & $\begin{array}{l}\text { Prolonged } \\
\mathrm{N}(\%)\end{array}$ & $\begin{array}{l}\text { Not } \\
\text { prolonged } \\
\text { N (\%) }\end{array}$ & & & \\
\hline \multirow[t]{2}{*}{ Residence } & Rural & 149(85.10) & $26(14.90)$ & $\begin{array}{l}1.86(1.12- \\
3.09)\end{array}$ & $\begin{array}{l}1.14(0.56- \\
2.29)\end{array}$ & 0.724 \\
\hline & Urban & $176(75.50)$ & $57(24.50)$ & 1.0 & 1.0 & \\
\hline \multirow[t]{3}{*}{ Time of arrival } & Moring & $141(71.20)$ & $57(28.80)$ & 1.0 & 1.0 & \\
\hline & Afternoon & $121(85.80)$ & $20(14.20)$ & $\begin{array}{l}2.45(1.39- \\
4.30)\end{array}$ & $\begin{array}{l}1.83(0.92- \\
3.69)\end{array}$ & 0.086 \\
\hline & Night & 63(91.30) & $6(8.70)$ & $\begin{array}{l}4.24(1.73- \\
10.35)\end{array}$ & $\begin{array}{l}3.19(1.14- \\
8.98)\end{array}$ & 0.028 \\
\hline \multirow[t]{2}{*}{ Date of arrival } & Work day & $242(75.90)$ & $77(24.10)$ & 1.0 & 1.0 & \\
\hline & Weekend & 83(93.30) & $6(6.70)$ & $\begin{array}{l}4.40(1.85- \\
10.45)\end{array}$ & $\begin{array}{l}4.25(1.63- \\
11.12)\end{array}$ & 0.003 \\
\hline \multirow{5}{*}{$\begin{array}{l}\text { Duration of } \\
\text { pain }\end{array}$} & $\leq 12$ hours & $42(85.70)$ & $7(14.30)$ & 1.0 & 1.0 & \\
\hline & 13-24 hours & $24(51.10)$ & $23(48.90)$ & $\begin{array}{l}0.17(0.65- \\
0.46)\end{array}$ & $\begin{array}{l}0.29(0.89- \\
0.98)\end{array}$ & 0.046 \\
\hline & $25-48$ hours & $43(74.10)$ & $15(25.90)$ & $\begin{array}{l}0.48(0.18- \\
1.29)\end{array}$ & $\begin{array}{l}0.69(0.20- \\
2.37)\end{array}$ & 0.559 \\
\hline & 49-72 hours & 73(73.000 & $27(27.00)$ & $\begin{array}{l}0.45(0.18- \\
1.12)\end{array}$ & $\begin{array}{l}1.09(0.35- \\
3.45)\end{array}$ & 0.897 \\
\hline & $\geq 73$ hours & $143(92.90)$ & $11(7.10)$ & $\begin{array}{l}2.17(0.79- \\
5.94)\end{array}$ & $\begin{array}{l}2.95(0.82- \\
10.54)\end{array}$ & 0.096 \\
\hline \multirow[t]{2}{*}{$\begin{array}{l}\text { Preexisting } \\
\text { comorbidity }\end{array}$} & Yes & 83(93.30) & $6(6.70)$ & $\begin{array}{l}4.40(1.85- \\
10.48)\end{array}$ & $\begin{array}{l}1.98(0.73- \\
5.30)\end{array}$ & 0.176 \\
\hline & No & $242(75.90)$ & $77(24.10)$ & 1.0 & 1.0 & \\
\hline \multirow[t]{2}{*}{ Triage category } & Read & $81(89.00)$ & $10(11.00)$ & $\begin{array}{l}5.04(2.25- \\
11.32)\end{array}$ & $\begin{array}{l}2.51(0.87- \\
7.23)\end{array}$ & 0.088 \\
\hline & Orange & $120(90.90)$ & 12(9.10) & $\begin{array}{l}6.22(2.92- \\
13.27)\end{array}$ & $\begin{array}{l}4.01(1.60- \\
10.05)\end{array}$ & 0.003 \\
\hline
\end{tabular}

*1.0 = reference category 


\begin{tabular}{|c|c|c|c|c|c|c|}
\hline \multicolumn{2}{|l|}{ Variables } & \multicolumn{2}{|c|}{ Length of stay } & \multirow{2}{*}{$\begin{array}{l}\text { COR }(95 \% \\
\text { Cl) }\end{array}$} & \multirow{2}{*}{$\begin{array}{l}\text { AOR }(95 \% \\
\text { Cl) }\end{array}$} & \multirow{2}{*}{$\begin{array}{l}\mathrm{P} \text { - } \\
\text { value }\end{array}$} \\
\hline & & $\begin{array}{l}\text { Prolonged } \\
N(\%)\end{array}$ & $\begin{array}{l}\text { Not } \\
\text { prolonged } \\
\mathrm{N}(\%)\end{array}$ & & & \\
\hline & Yellow & 79(70.50) & $33(29.50)$ & $\begin{array}{l}1.49(0.79- \\
2.78)\end{array}$ & $\begin{array}{l}1.35(0.63- \\
2.88)\end{array}$ & 0.441 \\
\hline & Green & $45(61.60)$ & $28(38.40)$ & 1.0 & & \\
\hline \multirow[t]{2}{*}{ Imaging study } & Yes & $216(88.20)$ & $29(11.80)$ & $\begin{array}{l}3.69(2.22- \\
6.12)\end{array}$ & $\begin{array}{l}2.82(1.49- \\
5.35)\end{array}$ & 0.001 \\
\hline & No & 109(66.90) & $54(33.10)$ & 1.0 & 1.0 & \\
\hline \multirow{2}{*}{$\begin{array}{l}\text { Got all ordered } \\
\text { medication }\end{array}$} & Yes & 179(73.70) & $64(26.30)$ & 1.0 & 1.0 & \\
\hline & No & $145(88.40)$ & $19(11.60)$ & $\begin{array}{l}2.73(1.56- \\
4.76)\end{array}$ & $\begin{array}{l}2.05(1.04- \\
4.03)\end{array}$ & 0.037 \\
\hline \multirow[t]{2}{*}{ Admit } & Yes & 154(86.50) & $24(13.50)$ & $\begin{array}{l}2.21(1.31- \\
3.73)\end{array}$ & $\begin{array}{l}1.46(0.78- \\
2.74)\end{array}$ & 0.236 \\
\hline & No & $171(74.30)$ & $59(25.70)$ & 1.0 & 1.0 & \\
\hline \multirow[t]{2}{*}{ Referral status } & Self & $188(75.20)$ & $62(24.80)$ & 1.0 & 1.0 & \\
\hline & $\begin{array}{l}\text { From other } \\
\text { health } \\
\text { institutions }\end{array}$ & 137(86.70) & $21(13.30)$ & $\begin{array}{l}2.15(1.25- \\
3.69)\end{array}$ & $\begin{array}{l}0.82(0.37- \\
1.82)\end{array}$ & 0.624 \\
\hline \multirow{2}{*}{$\begin{array}{l}\text { Number of } \\
\text { investigations }\end{array}$} & 1 & $27(65.90)$ & $14(34.10)$ & 1.0 & 1.0 & \\
\hline & $\geq 2$ & $298(81.20)$ & $69(18.80)$ & $\begin{array}{l}2.24(1.12- \\
4.49)\end{array}$ & $\begin{array}{l}1.28(0.52- \\
3.13)\end{array}$ & 0.594 \\
\hline
\end{tabular}

\section{Discussion}

Patient length of stay is a major indicator reflecting how well an ED is working, and the overall efficiency and quality of service of an ED(32).Prolonged length of stay is positively associated with morbidity, mortality, and negative satisfaction, also length of stay is a reasonable substitution for resource consumption and is vital for the planning and management of care(22). This study attempted to determine the magnitude and factors associated with pediatric emergency department length of stay among patients attending the pediatric emergency department of Wolaita Sodo University Teaching referral hospital.

This study demonstrated that an appreciably high $79.7 \%(95 \% \mathrm{Cl} ; 75.7,83.6)$ of pediatrics patients stay for greater than 24 hours in the pediatric emergency department. High proportion of prolonged pediatrics 
emergency department length of stay is a universal problem and variations regarding such length of stay in terms of prevalence vary across the globe; $31.3 \%, 25.7 \%, 22 \%, 10.2 \%, 16.4 \%$ in Guangzhou China, northern Taiwan, Boston USA Iran , and Nigeria respectively $(4,7-9,33)$. The possible reason for these discrepancies might be due to the difference in health care system level, or advancements in medical health services, the difference in the number of health professionals in Guangzhou, China ED has 5 general physicians, 16 senior pediatric residents and 22 nurses(7) while in the current study the ED have 4 pediatrician, 5 general physicians, and 7 nurses(27) the study in Boston Children's Hospital USA includes study participant only pediatrics emergency case with mental illness(33) in contrast the current study includes all emergency cases in wait Sodo pediatrics emergency department.

In addition, variation of criteria used across settings, for instance, the study done in Nigeria used a garter $\geq 72$ hours for a prolonged length of stay(9)nevertheless the current study used $>24$ hours based on Ethiopian hospital services transformation guidelines criteria for length of stay(34). The aforementioned might be the possible reason for an increased prevalence of prolonged pediatrics ED length of stay in the current study.

The present study showed that night-time arrival to PED was significantly associated with prolonged length of stay at PED. This is in accordance with other studies conducted in China, Indonesia , and the USA $(3,35,36)$.

The possible explanation could be due to the fact that the hospital may not admit to inpatient or discharge patients during the night shift; night shift arrivals to ED need to wait until daytime to be admitted or discharged(34). In addition, expert consultation and diagnostic or therapeutic modalities are less available at night compared to daytime. However, this is contradicted with studies done in Egypt and Switzerland which stated that morning arrival is a factor for a prolonged length of stay in pediatrics $\mathrm{ED}(14,37)$. This discrepancy might be due to the difference in population characteristics, distinct arrival patterns, and staffing policy for each hospital or region. This information can be valuable at the administrative level for planning providers.

Similarly, the findings of this study showed that weekend arrival to PED was significantly associated with prolonged PED length of stay. This finding is in agreement with other studies was conducted in Taiwan and China $(8,38)$.This might be due to decreased number of health professionals on weekends and experts (senior physicians, radiologists) may not be available on a weekend compared to workdays.

This study showed that triage category (orange) was significantly associated with prolonged length of stay. The same is true in the findings of the studies conducted in Indonesia, USA, China, Switzerland $(3,7$, $14,36)$. This might be due to the patients on triage level II are on a high level of acuity when the acuity level of the disease is increased, the patients come in need of lots of care, and the emergency intervention's required more time, intensive treatment was given, likewise, the nature of the disease in the pediatrics population by itself is challenging to manage easily for health professionals, and the higher the acuity level the more challenged and physicians require more time to decide the appropriate place for the patient's weather inpatient ward, refer to other hospital or discharge. In addition, patients with high 
acutely level may need experts (pediatrician) and more investigation modalities, this this thing may contribute to prolonged LOS by increased time to wait for the pediatrician and found ordered investigation.

The findings of this study also showed that having an ordered an imaging study was significantly associated with prolonged PED length of stay, this is in line with a study conducted in Taiwan (36). The possible explanation might be because imaging investigations are important for accuracy and confirming diagnosis of the patient, which is vital for making decisions by physician whether the patient is referred to another hospital, discharged or admitted. In addition, most imaging investigations take more time than other investigations; those things may lead to raised pediatrics ED length of stay.

This study also showed that patients who did not find ordered medications in the hospital were significantly associated with prolonged PED length of stay. The possible justification could be due to that not getting the medications in the hospital could result in increased time for finding medications outside the hospital, and result in a late intake of the prescribed medication, and delayed recovery.

Moreover, this study also showed that duration of pain had a significant effect on PED length of stay. The odds of PED length of stay were $71 \%$ less likely in a patient who came with the duration of $13-24$ hours compared to patients with duration of pain $\leq$ of 12 hours. This might be due to that patients with duration of pain 13-24 hours might come to less acute life treating emergencies, which can be easily manageable. Likewise, less acute cases may not need intensive care, the diagnosis modality for confirmation of a suspected cases to provide appropriate treatments, and those could be possible justifications. There this implicated that the less acute cases are short stay in PED who were coming with short duration of pain.

\section{Limitations of the study}

\section{Limitation}

Variables like duration of pain, time taken from ordered by physician until discharge, referred, and admitted were prone to recall biased, to overcome this the data were collected at the point of treatment .

\section{Conclusion}

This research has demonstrated the proportion of prolonged pediatrics emergency department length of stay was high. Night time arrival, weekend day arrival, triage categories, duration of pain, imaging study, and getting ordered medication in the hospital were found to be a significantly associated with pediatrics emergency department length of stay. Therefore, appropriate interventions are warranted to be designed and implemented emphasizing the aforementioned associated factors.

\section{Declarations}

Ethics approval and consent to participate 
Ethical clearance was issued from the School of Nursing Research ethical Review Committee on behalf of the University of Gondar in a letter Ref. No. S/N/2013/0/2021.A formal ethical and cooperation letter was delivered to Wolaita Sodo University Teaching and referral hospital head officer (research officer), then the head of the facility permit, and directed a permission letter to the ED unit team leader/coordinator. Informed consent was obtained from the study participants on the right of participation or refusal to the study. Confidentiality of the information was kept for each study participant by coding the data.

\section{Consent for publication}

Not applicable

\section{Availability of data and materials}

All data and materials relevant to this study are available from the corresponding author whenever required.

\section{Competing interests}

The authors declare that they have no any competing interests for publication.

\section{Authors' contributions}

NT: Made a great contribution in designing and shaping the study methodology, ensuring the appropriateness of the tool, supervised and extensively involved in the analysis, writing up, and interpretation of the data. A.T: considerably involved in the proposal development process and tool modification, assisting data analysis and interpretation. MG: ensured the appropriateness of the tool, supervised and extensively involved in the analysis written up.

\section{Acknowledgments}

We would like to express our deepest gratitude to the University of Gondar for its holistic support. We would also like to express our gratitude to the Wolaita Sodo University Teaching and referral hospital, and ED health workers for their bottomless cooperation. Moreover, our special thanks go to data collectors and supervisors for their endless assistance and all study participants who took part in the study without any reluctance. Lastly, we have recognized Research square for making visible the research as a preprint to scholars (39).

\section{Authors' information}

NT (MSc, Assistant Professor): Lecturer at University of Gondar, College of Medicine and Health Sciences, School of Nursing, Department of Pediatrics and Child Health Nursing. AT(MSc in Pediatric and Child Health Nursing): Lecturer at University of Gondar, College of Medicine and Health Sciences, School of Nursing, Department of Pediatrics and Child Health Nursing. 
KB (MSc in Pediatric and Child Health Nursing): Lecturer at Wolaita Sodo University, College of Health and Medical Sciences, school of Nursing Department of pediatrics and neonatology department.

MG (MSc in emergency and critical care nursing): Lecturer at Wolaita Sodo University, College of Health and Medical Sciences, school of Nursing Department of emergency and critical care nursing.

\section{Abbreviations}

\begin{tabular}{ll} 
ED & Emergency Department \\
\hline EM & Emergency Medicine \\
\hline ETAT & Emergency Triage Assessment and Treatment \\
\hline ETB & Ethiopian Birr \\
\hline FDMOH & Federal Mister of Health \\
\hline IMNCI & Integrated Management of Newborn and Childhood Illness \\
\hline LMICs & Low and Middle-Income Countries \\
\hline LOS & Length of Stay \\
\hline PEDLOS & Pediatrics Emergency Department Length of Stay \\
\hline PLOS & Prolonged Length of Stay \\
\hline SPSS & StatisticalPackagefor Social Sciences \\
\hline WSUTRH & Wolaita Sodo University Teaching and Referral Hospital
\end{tabular}

\section{References}

1. Bashkin O, Caspi S, Haligoa R, Mizrahi S, Stalnikowicz R. Organizational factors affecting length of stay in the emergency department: initial observational study. Israel journal of health policy research. 2015;4(1):38.

2. Riney LC, Brokamp C, Beck AF, Pomerantz WJ, Schwartz HP, Florin TA. Emergency medical services utilization is associated with community deprivation in children. Prehospital Emergency Care. 2019;23(2):225-32.

3. Kusumawati $\mathrm{HI}$, Magarey $\mathrm{J}$, Rasmussen P. Analysis of factors influencing length of stay in the Emergency Department in public hospital, Yogyakarta, Indonesia. Australasian emergency care. 2019;22(3):174-9.

4. Hosseininejad SM, Aminiahidashti H, Pashaei SM, Khatir IG, Montazer SH, Bozorgi F, et al. Determinants of prolonged length of stay in the emergency department; a cross-sectional study. 
Emergency. 2017;5(1).

5. Ahmed AA, Ibro SA, Melkamu G, Seid SS, Tesfaye T. Length of Stay in the Emergency Department and Its Associated Factors at Jimma Medical Center, Southwest Ethiopia. Open Access Emergency Medicine: OAEM. 2020;12:227.

6. Simkhada P, Acharya S, Lama R, Dahal S, Lohala N, Thapa A. Emergency Stay Duration of Patients in Emergency Department of A Tertiary Care Hospital in Nepal: A Descriptive Cross-sectional Study. Journal of the Nepal Medical Association. 2020;58(222).

7. Xie J, Lin Y, Kissoon N. Factors associated with prolonged stay in a pediatric emergency observation unit of an urban tertiary children's hospital in China. Pediatric emergency care. 2013;29(2):183-90.

8. Li S-T, Chiu N-C, Kung W-C, Chen J-C. Factors affecting length of stay in the pediatric emergency department. Pediatrics \& Neonatology. 2013;54(3):179-87.

9. Enyuma CO, Anah MU, Pousson A, Olorunfemi G, Ibisomi L, Abang B, et al. Patterns of paediatric emergency admissions and predictors of prolonged hospital stay at the children emergency room, University of Calabar Teaching Hospital, Calabar, Nigeria. African health sciences. 2019;19(2):191023.

10. Boudi Z, Lauque D, Alsabri M, Östlundh L, Oneyji C, Khalemsky A, et al. Association between boarding in the emergency department and in-hospital mortality: A systematic review. PloS one. 2020;15(4):e0231253.

11. Hsu C-C, Chan H-Y. Factors associated with prolonged length of stay in the psychiatric emergency service. PloS one. 2018;13(8):e0202569.

12. Baniasadi T, Kahnouji K, Davaridolatabadi N, Teshnizi SH. Factors affecting length of stay in Children Hospital in Southern Iran. BMC health services research. 2019;19(1):949.

13. Zhang Z, Bokhari F, Guo Y, Goyal H. Prolonged length of stay in the emergency department and increased risk of hospital mortality in patients with sepsis requiring ICU admission. Emergency Medicine Journal. 2019;36(2):82-7.

14. Hofer KD, Saurenmann RK. Parameters affecting length of stay in a pediatric emergency department: a retrospective observational study. European journal of pediatrics. 2017;176(5):591-8.

15. Lateef A, Lee SH, Fisher DA, Goh W-P, Han HF, Segara UC, et al. Impact of inpatient Care in Emergency Department on outcomes: a quasi-experimental cohort study. BMC health services research. 2017;17(1):1-8.

16. Harel-Sterling M, Diallo M, Santhirakumaran S, Maxim T, Tessaro M. Emergency department resource use in pediatric pneumonia: point-of-care lung ultrasonography versus chest radiography. Journal of Ultrasound in Medicine. 2019;38(2):407-14.

17. Chiu I-M, Lin Y-R, Syue Y-J, Kung C-T, Wu K-H, Li C-J. The influence of crowding on clinical practice in the emergency department. The American journal of emergency medicine. 2018;36(1):56-60.

18. Negari KG, Rodamo KM, Hirigo AT. Factors associated with the length of stay in emergency departments in Southern-Ethiopia. BMC research notes. 2019;12(1):239. 
19. Valitutti F, Zenzeri L, Mauro A, Pacifico R, Borrelli M, Muzzica S, et al. Effect of population lockdown on pediatric emergency room demands in the era of COVID-19. Frontiers in pediatrics. 2020;8.

20. Miller R. Nurse-Driven Protocols in the Pediatric Emergency Department: A Systematic Review. 2020.

21. Anyanwu OU, Ezeanosike OB, Ezeonu CT. Pattern and outcome of admissions at the children emergency room at the Federal Teaching Hospital Abakaliki. African Journal of Medical and Health Sciences. 2014;13(1):6.

22. Jofiro G, Jemal K, Beza L, Heye TB. Prevalence and associated factors of pediatric emergency mortality at Tikur Anbessa specialized tertiary hospital: a 5 year retrospective case review study. BMC pediatrics. 2018;18(1):1-10.

23. Moskop JC, Geiderman JM, Marshall KD, McGreevy J, Derse AR, Bookman K, et al. Another look at the persistent moral problem of emergency department crowding. Annals of emergency medicine. 2019;74(3):357-64.

24. Morley C, Unwin M, Peterson GM, Stankovich J, Kinsman L. Emergency department crowding: A systematic review of causes, consequences and solutions. PloS one. 2018;13(8):e0203316.

25. Mersha A, Worku T, Shibiru S, Bante A, Molla A, Seifu G, et al. Neonatal sepsis and associated factors among newborns in hospitals of Wolaita Sodo Town, Southern Ethiopia. Research and Reports in Neonatology. 2019;9:1-8.

26. Batiro B, Demissie T, Halala Y, Anjulo AA. Determinants of stunting among children aged 6-59 months at Kindo Didaye woreda, Wolaita Zone, Southern Ethiopia: Unmatched case control study. PloS one. 2017;12(12):e0189106.

27. WSUHR, editor Wolaita Sod university human resource lizens offices Open Forum Infectious Diseases; 2019.

28. Tabriz AA, Trogdon JG, Fried BJ. Association between adopting emergency department crowding interventions and emergency departments' core performance measures. The American Journal of Emergency Medicine. 2020;38(2):258-65.

29. Smith JL, De Nadai AS, Petrila J, Storch EA. Factors associated with length of stay in emergency departments for pediatric patients with psychiatric problems. Pediatric emergency care. 2019;35(10):716.

30. Ababa A. Federal democratic republic of Ethiopia ministry of health. Ethiopia: Postnatal Care. 2003.

31. <Ethiopian Hospital Services Transformation Guideline Volume 1.pdf>.

32. Karpenko Y. How to Embrace Change: Provincial Unemployment After the 2008 Recession. 2014.

33. Hoffmann JA, Stack AM, Monuteaux MC, Levin R, Lee LK. Factors associated with boarding and length of stay for pediatric mental health emergency visits. The American journal of emergency medicine. 2019;37(10):1829-35.

34. FMOH, editor ETHIOPIAN HOSPITAL SERVICES TRANSFORMATION GUIDELINES Volume 1, September 20162016. 
35. Chaou C-H, Chiu T-F, Yen AM-F, Ng C-J, Chen H-H. Analyzing factors affecting emergency department length of stay-using a competing risk-accelerated failure time model. Medicine. 2016;95(14).

36. Nelson KA, Boslaugh SE, Hodge D. Risk factors for extremely long length-of-stay among pediatric emergency patients. Pediatric emergency care. 2009;25(12):835-40.

37. Nassar MMAA, Hassan BA, El-Saadany HF. Factors Affecting Length of Stay in Pediatric Emergency Department in Zagazig University Hospital. The Egyptian Journal of Hospital Medicine. 2020;81(4):1872-7.

38. Chaou C-H, Chen H-H, Chang S-H, Tang P, Pan S-L, Yen AM-F, et al. Predicting length of stay among patients discharged from the emergency department-using an accelerated failure time model. PloS one. 2017;12(1):e0165756.

39. https://www.researchsquare.com/submit.

\section{Figures}

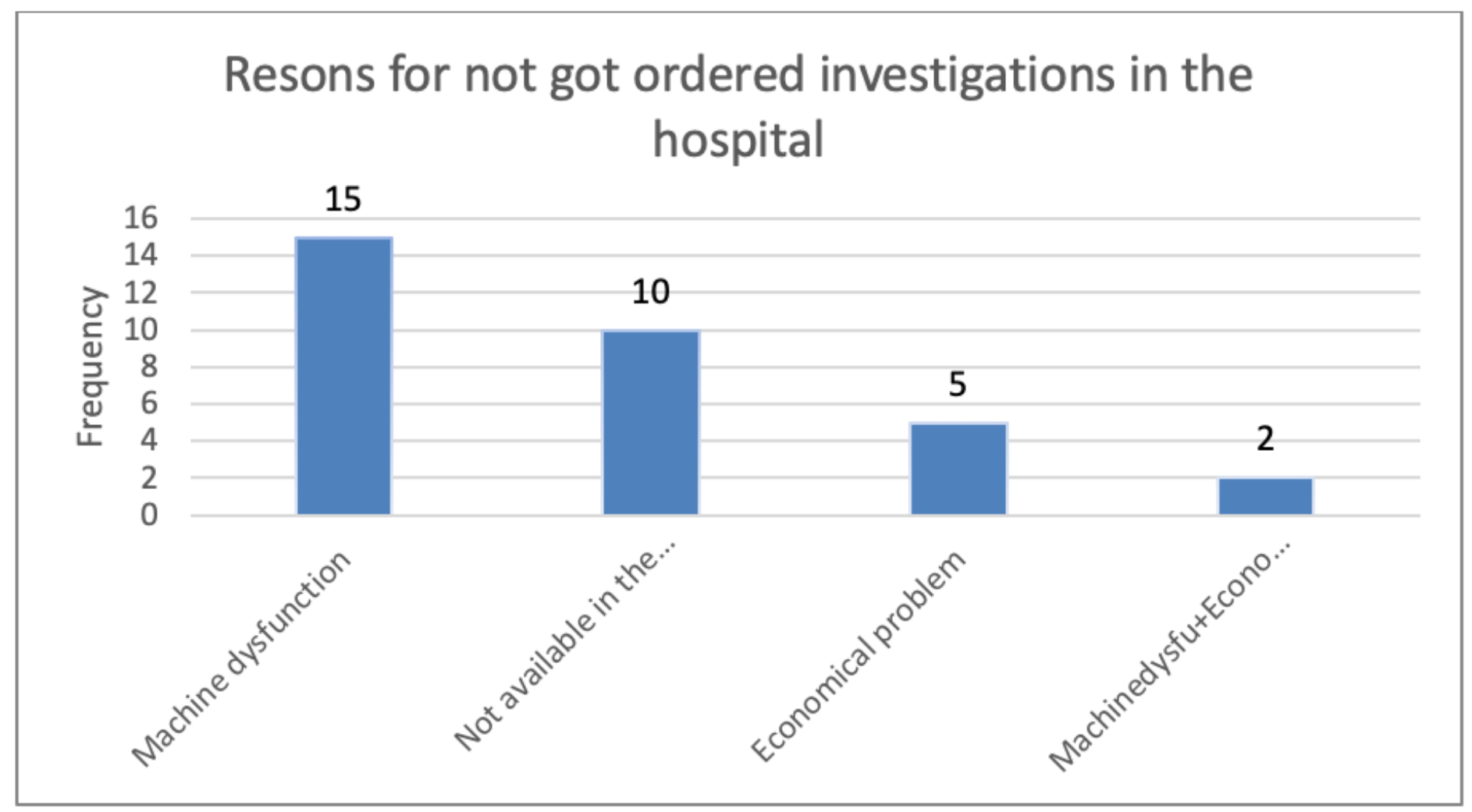

\section{Figure 1}

Reasons for not got the ordered investigation in pediatrics emergency department of Wolaita Sodo University Teaching and Referral Hospital, South Ethiopia Jun 2021. 


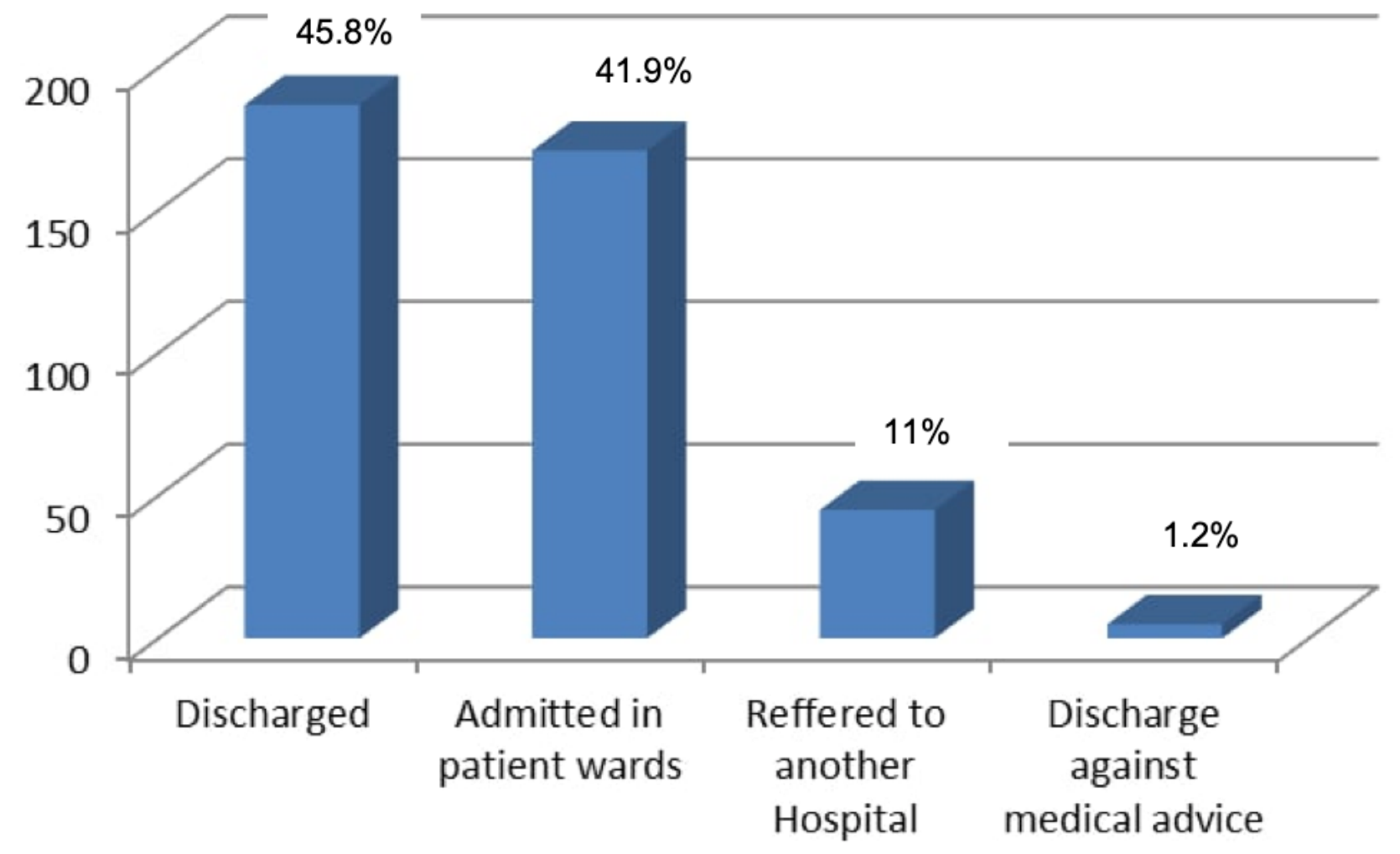

Figure 2

Outcome of pediatric patent from pediatrics emergency department of Wolaita Sodo University Teaching and Referral Hospital, South Ethiopia Jun 2021. ( $n=408)$ 


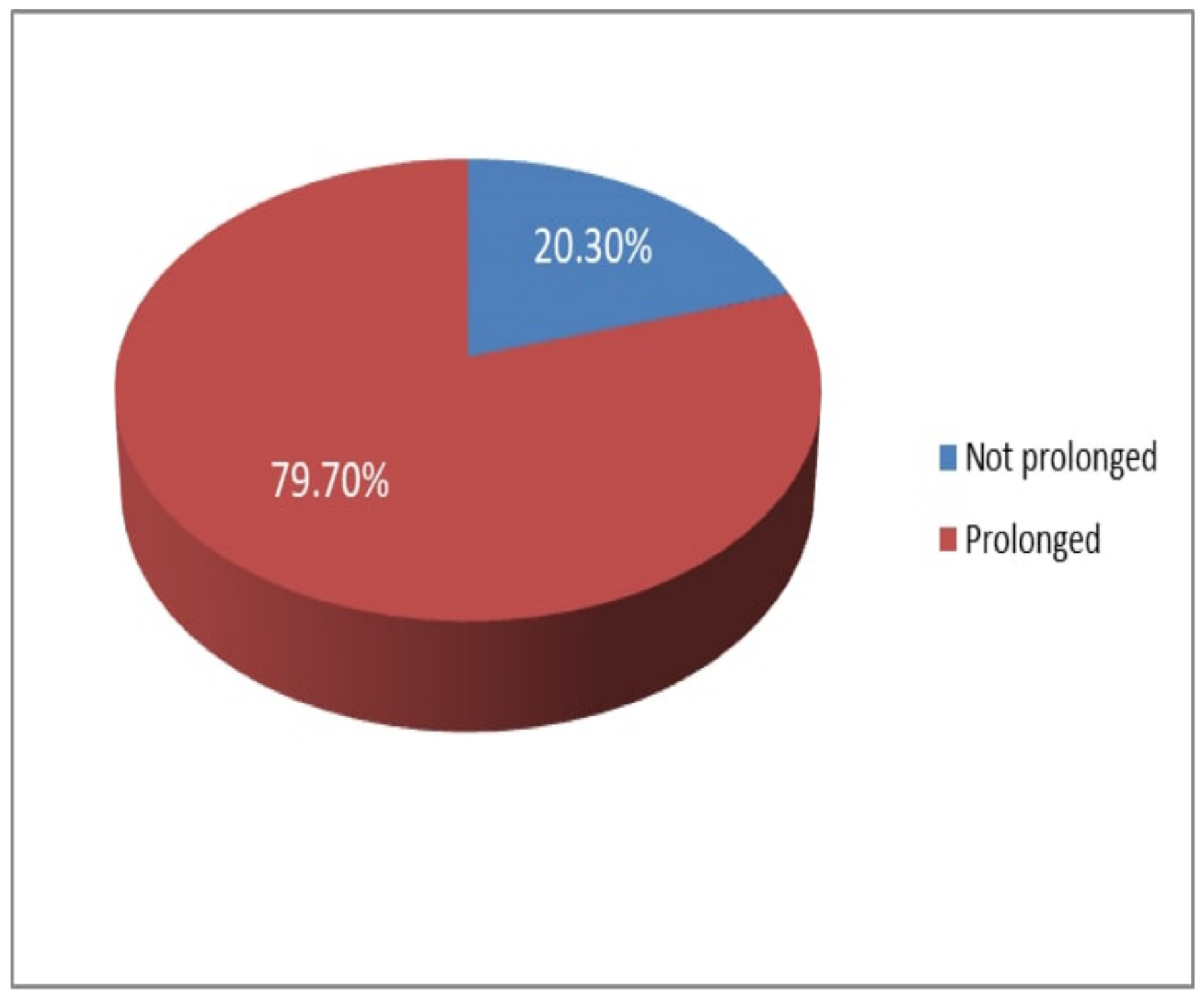

Figure 3

Prevalence of pediatrics emergency department length of stay in Wolaita Sodo University Teaching and Referral Hospital, South Ethiopia Jun 2021. ( $n=408)$ 